\title{
Hospital bathroom ergonomics: Safety, usability and accessibility issues
}

\author{
Edda Maria Capodaglio \\ Salvatore Maugeri Foundation, IRCCS, Scientific Institute of Pavia, via Severino Boezio, Pavia, Italy \\ Correspondence: Edda Maria Capodaglio. Address: Via S Boezio 26, 27100 Pavia, Italy. Email: edda.capodaglio@fsm.it \\ Received: March 13, 2014 \\ Accepted: June 26,2014 \\ Online Published: July 11, 2014 \\ DOI : $10.5430 / c n s . v 2 n 4 p 1$ \\ URL: http://dx.doi.org/10.5430/cns.v2n4p1
}

\section{Abstract}

The safety, usability and accessibility of hospital bathrooms are important requirements for both patients and assistant nurses. Most frequently noted the critical factors in rehabilitation wards, in determining optimal management of patients' motor impairments, are space and equipment adequacy. Moreover, a bathroom is an essential part of any living space, and as such, has the potential to greatly impact on the patient's recovery process.

Current regulations and universal design define criteria for the physical layout of hospital bathrooms. Nonetheless, their practical use often discloses inconsistencies with regard to space and equipment that may jeopardize safety and ergonomics of both patients and personnel.

This study explores safety, usability and accessibility issues in hospital bathrooms with a participative ergonomic approach. 32 hospital bathrooms of an Italian rehabilitation ward were inspected according to space and furniture features, and their use was simulated by dependent and independent patients. Obstacles to independent use and assisted transfers were assessed by the patients and the assisting nurses by reports and by on-site observation of physical constraints.

The most critical aspects in the bathrooms' layout involved space (26\% less than the recommended value), inaccessibility with devices (67\% with wheelchair, $90 \%$ with mobile hoist), inadequate location and inconsistency of elements of hygiene. Inadequate space and missing elements create an unsafe environment which may damage both nurses and patients, by requiring unsuitable movements, awkward postures which increase the risk of fall or injury. Greater attention to the ergonomics of hospital bathrooms could improve safety, usability and accessibility for any user and could contribute to overcoming adverse situations that significantly affect daily hospital routine.

\section{Key words}

Hospital bathroom, Safety, Usability, Accessibility

\section{I ntroduction}

A major challenge of the present healthcare system is to grant the safety of the workers and the patients, besides maintaining and enhancing the quality of care ${ }^{[1]}$. The increasing demand of delivering healthcare assistance to complex patients by staff with limited resources poses a serious risk of work-related overload ${ }^{[2-4]}$; the risk is also recognized by international norms which urge adoption of ergonomic assessment and preventive approaches ${ }^{[5]}$. Risk prevention should be based on the analytical assessment of all the potential risk determinants carried out through a participatory approach. 
The environment itself, in which patients are handled may constitute a hazard if inadequate; all spaces should be considered for equipment use and handling postures. Since many personal hygienic and nursing tasks take place in the bathroom, proper design, furnishing and maintenance of this area are important aspects for safety at work and appropriateness of care ${ }^{[6]}$.

Adequate and regular use of bathrooms contributes to the patient's self care and maintenance and generally helps in the fight against infections ${ }^{[7-9]}$. Safety, accessibility and usability of the bathroom allow the patient to maintain motor ability and reinforce independence, thus contributing to many positive outcomes ${ }^{[10]}$. On the contrary, structural inadequacies in the bathrooms could slow down the recovery process and negatively affect the effectiveness of nurse delivery.

While organizational and individual factors are usually thoroughly considered in healthcare safety, space design and accessibility are often almost overlooked and/or delegated to architectural design questions. It has been claimed that, if compared to other industrial and working sectors, a marked backwardness in the healthcare system exists in the compliance with modern design criteria ${ }^{[11]}$, together with a still partial implementation of the ergonomic and user centered design guidelines ${ }^{[7]}$. It has even been suggested that hospital design does not meet the explicit goal of enhancing staff and patient's safety through facility design innovations ${ }^{[10]}$.

A fundamental problem in hospital bathrooms is the provision of adequate space, in order to allow proper movements, assisting the patient or maneuvering equipment ${ }^{[12-14]}$. Deficiencies in the standards of hospital inpatient washing and bathing facilities usually concern access to wheelchair users, insufficient equipment, and other aspects limiting comfort and dignity ${ }^{[15,16]}$. Defects in the hospital bathroom systematically affect functionality of transfers, efficiency of the hospital equipment and the staffing effectiveness ${ }^{[17,18]}$. Other inadequacies related to the bathrooms are evident from the high frequency of the patient falls occurring in this area (or on the way to-from the bathroom), and the correlated injuries ${ }^{[19]}$.

In Italy the norms DM 236/89 and DPR 503/96 apply technical requirements to private and public buildings to gain accessibility according to a barrier-free perspective. The norms identify minimal spaces and requirements and tend to remove any physical hindrance limiting a safe and proficient use for the wheel-chaired individual (see Table 1).

Table 1. Minimal dimensional requirements for hospital bathrooms, according to the Italian norms

Minimal surface area $3.25 \mathrm{~m}^{2}$

Doors' net minimum width of $80 \mathrm{~cm}$

Free room for wheelchair maneuvering among hygienic elements

Wall-mounted hygienic furnishing, equipped with handrails

Floor drained shower, furnished with wall mounted seat

Emergency alarm call system

Sink equipped with lever taps and a mirror above

Mainly focused on accessibility, the norms refer to the concept of adaptation, offering a positive approach to disability; however functional inadequacies of this physical layout emerge in the context of the healthcare assistance tasks, as when one or two operators tend the patient or when the user is a fragile elderly or an obese patient, or all of the above (see Table 2). Of particular concern are the aspects concerning workers' safety ${ }^{[7,20]}$ and accessibility and usability by the patients ${ }^{[8,21]}$.

There have been variable design approaches to safety, accessibility and usability in the hospital. 
Safety design in hospital was traditionally connected to prevention of falls ${ }^{[8,12,18,22]}$ and infections ${ }^{[23]}$, thereby resulting in recommendations to fix unsafe conditions which could negatively impact on patients' transfers, or to install cleanser suppliers and to spread hygienic instructions promoting more efficient and frequent hand washing. However safety was scarcely considered relative to bathroom use and its related preventive interventions were not specifically targeted to reduce the biomechanical overload in assistant nurses during assistance to toileting-related tasks.

Table 2. Critical aspects not covered by the current normative regulations (adapted from Fink)

\begin{tabular}{|c|c|}
\hline \multirow[t]{2}{*}{ Space/clearance } & Easy maneuvering in and out with devices \\
\hline & Bathroom door swinging/sliding, easy usable by a wheel chaired patient \\
\hline \multirow[t]{2}{*}{ Assisting nurses } & Space accommodation for two assistants and the equipment \\
\hline & $\begin{array}{l}\text { Provision for installation of a ceiling mounted lift extending } \\
\text { from the patient room into the bathroom }\end{array}$ \\
\hline \multirow[t]{5}{*}{ Obese patients } & $\begin{array}{l}\text { Bathroom entrance accommodating large patients, patients on wheelchair/walkers and patients } \\
\text { attached to a piece of equipment }\end{array}$ \\
\hline & Shower area and seat fitting to obese patient \\
\hline & Bathroom door completely close when a person is sitting on toilet \\
\hline & Floor mounted steel toilet, adequate in weight bearing and sturdiness \\
\hline & Bariatric commode chair on casters, hygienic seat or bench \\
\hline \multirow[t]{7}{*}{ Frail patients } & Handrails positioned so that patients can easily lower down and push themselves back up \\
\hline & Handrails on both sides of toilet \\
\hline & Handrails on both sides of the shower seat \\
\hline & All handrails in the bathroom limit the need to bend, reach, turn \\
\hline & Sink handrails which permit on easy reach the patient to steady himself on \\
\hline & Countertop located at a height that minimize bending and reaching \\
\hline & $\begin{array}{l}\text { Soap dispenser, paper towel holder located close to each other and within easy reach of the } \\
\text { patient at the sink }\end{array}$ \\
\hline \multirow[t]{3}{*}{ Location/anthropometry } & Elements within bathroom accommodate the majority of user population \\
\hline & Proper toilet seat height \\
\hline & Elements positioned so that minimize bending, turning, reaching \\
\hline Labeling and consistency & $\begin{array}{l}\text { Intuitive use and affordance of elements (lever taps, water dispenser, handrails/towel holders, } \\
\text { emergency call button) }\end{array}$ \\
\hline
\end{tabular}

Table 3. Workspace for typical working activities (adapted from Nelson)

\begin{tabular}{lcc}
\hline \multirow{2}{*}{ Type of task } & \multicolumn{2}{c}{ Workspace } \\
\cline { 2 - 3 } & Minimum (mm) & Optimal (mm) \\
\hline One person assisting frontally & 810 & 1000 \\
One person assisting laterally & 610 & 760 \\
Pivot $180^{\circ}$ wheelchair & 1500 & 1800 (bariatric) \\
Pivot $180^{\circ}$ floorlift & 1800 & 2440 (bariatric) \\
Pivot $180^{\circ}$ geriatric chair & 1800 & 2100 (bariatric) \\
Stretcher circulation & 915 & 1000 \\
\hline
\end{tabular}

Accessibility was traditionally interpreted as the possibility by a disabled individual to move, transfer and perform basic tasks by wheelchair, thereby the regulation recommends free spaces for the wheelchair maneuvers, adequate supports and furnishing for postural transfers. 
Accessibility was yet scarcely considered in relation to the assistance tasks, as one or more nurses tend for a patient whose size, motion and balance could substantially vary. In these situations additional space and equipment may be required (see Table 3).

Usability, as defined by the international norm ISO 9241, refers to the possibility of having an effective, efficient and satisfactory experience by the user. Its assessment was mainly investigated in commercial products and software ${ }^{[24]}$, but minimal literature exists about usability of the hospital facilities; one study explicitly mentions problems experienced by nurses performing assistance tasks in the hospital bathroom ${ }^{[21]}$, while others try to define exactly the physical requirements to fit the patients' needs ${ }^{[19,25]}$. The impact of the physical layout on organizational and technological factors inside the hospital system was discussed by Boston-Fleischauer (2008), who advocates for an increasingly evidence-based healthcare facility design which could benefit patient safety and health outcomes.

The aim of this study was to capture and analyze safety, accessibility and usability aspects detected through an ergonomic participative survey relative to the bathroom's physical layout, in order to contribute to a deeper comprehension of the ergonomic aspects concerning this particular area of care.

\section{Materials and methods}

A participative ergonomic survey was conducted in 32 bathrooms (2 specially equipped bathrooms located in the corridors, and 30 en-suite bathrooms) of a rehabilitation ward in an Italian hospital.

The survey aimed at capturing and organizing the full range of ergonomic related problems that patients and assistant nurses experience while performing toileting related tasks in bathrooms, focusing on safety, accessibility and usability.

The survey was conducted by a team consisting of one professional ergonomist, one technician, the assistant nurses and the accompanying chief nurse. In-patients also participated voluntarily in simulation trials, selected if included in the following criteria: cooperation and understanding ability, level A-C according to the RAI classification ${ }^{[27]}$, absence of clinical complications.

The protocol used for the survey was as follows:

Each bathroom was initially visited by the ergonomist and the technician, and metric variables were taken: dimensions of the surface areas, width of the bathroom's entrance door and its angular opening, type and location of the hygienic elements (toilet, sink, bidet, shower) and toiletries (shelf, towel holder, coat hooks, soap dispenser, taps and handles), bath aids and handrails. The physical layout and dimensions of each bathroom were defined and documented.

A practical simulation relative to access and use of the bathroom was performed by nurses and inpatients: patients classified as A simulated the independent use; patients classified as B and C simulated the dependent use and were assisted by nurses, using the following device according to the patient's characteristics and needs: hygiene-seat, wheelchair, mobile hoist lift, shower-chair, shower-stretcher. These devices were selected as the most common in the rehabilitation ward. The simulation included the following phases: transiting bed-tobathroom, entering the bathroom, simulating the approach to toilet and sink, performing stand-to-sit and sit-to-stand transfers, simulating the approach to shower. Video frames during critical phases of the simulation trial were captured in order to provide proof of these situations. During each simulation the ergonomist annotated any difficulty or problem that arose from the patient or the assisting nurse by performing the task, revealed by unsuitable or clumsy movements. 
Immediately following every trial, a brief report was obtained from the participants about any perceived problem that emerged during the performance, and they were asked to identify the layout related inadequacies which were considered the cause.

The results were interpreted in the light of the ergonomic criteria, in order to identify the main obstacles to a safe use and to allow for possible solutions.

\section{Results}

The two specially equipped bathrooms located in the corridors and the 30 en-suite bathrooms were analyzed in each singular aspect (see Table 4).

\subsection{Dimensions}

The surface area was largest in the two specially equipped bathrooms $\left(7.80 \mathrm{~m}^{2}-7.75 \mathrm{~m}^{2}\right)$ which also were endowed with many ergonomic features (adjustable shower stretcher, handrails at toilet and shower), but unfortunately they were both used as storage rooms to allocate bulky equipment, due to a lack of other storage spaces in the ward. Among the 30 en-suite bathrooms, 8 cases (26\%) presented a surface area below the normative value.

\subsection{Detail and location of hygienic elements}

The 30 en-suite bathrooms shared some common features: doors externally opening with handle at $105 \mathrm{~cm}$ height; skid-proof floors; floor drained shower without raised edge; external light switch at $90 \mathrm{~cm}$ height; emergency alarm reachable by a fallen patient and near toilet; shelf fixed at $120 \mathrm{~cm}$ height, two coat hooks at $160 \mathrm{~cm}$ height, a waste bin. Handrails were provided only in some bathrooms and they were of various types (horizontal, vertical, folding) and fixed at variable heights $(79 \mathrm{~cm}-90 \mathrm{~cm}) .56 \%$ of hospital bathrooms were endowed with handrails near the toilet, $16 \%$ with handrails near the sink, and $86 \%$ with handrails near the shower area. The handrails' appearance (shape, color, size, location) was very similar to the towel holders, and the color contrast with the rear wall was mild. All the sinks were equipped with lever taps, a mirror above at different heights, a towel holder.

Although all the bathroom contained wall-mounted hygienic elements, they were inconsistent in sequence and height location: the toilet could be mounted at an height between $41 \mathrm{~cm}$ and $48 \mathrm{~cm}$, the bidet between $40 \mathrm{~cm}$ and $48 \mathrm{~cm}$, the shower seat between $49 \mathrm{~cm}$ and $59 \mathrm{~cm}$, the sink between $78 \mathrm{~cm}$ and $83 \mathrm{~cm}$, the mirror between $210 \mathrm{~cm}-197 \mathrm{~cm}$ (superior edge) and $130 \mathrm{~cm}-115 \mathrm{~cm}$ (inferior edge).

Even when a bathroom's surface area was large, usability in it could be hampered by inadequate space distribution and furnishing, as occurred when the access to the toilet was unsupported by handrails or when the shower seat was missing (46\% of cases).

The location of elements to be reached by the patient was considered: the toilet flushing and the toilet paper holder could be placed on the rear as on lateral wall at variable heights.

Coat hooks and shelf were fixed on the wall at $160 \mathrm{~cm}$ and $120 \mathrm{~cm}$ height, both unreachable by a seated patient.

\subsection{Accessibility}

Restricted rooms were tolerable to most independent patients, but were difficult to access by assisted patients ,due to unfit space for the assisting nurse and for maneuvers with equipment. Access from bedroom to en-suite bathroom was sometimes hampered by protruding elements or edges (radiators, furniture) with enhanced risk of bumping or increased difficulty in maneuvering devices. Access through the door was difficult (33\% of cases) when the door opening was limited. The bed-to-bathroom path could be performed differently according to the device being utilized (see Table 5). 
Transfer of a dependent patient from bed to shower-stretcher up to the corridor bathroom was impossible in 13 bedrooms due to insufficient door width or limited space inside room to maneuver the shower-stretcher.

Table 4. Dimensional characteristics of the en suite (n. 1-30) and of the corridor (n. 31, 32) bathrooms

\begin{tabular}{|c|c|c|c|c|c|c|c|c|c|c|c|c|c|c|}
\hline \multirow{3}{*}{$\begin{array}{l}\text { Toilet } \\
\text { n. }\end{array}$} & \multirow{3}{*}{$\begin{array}{l}\text { Area } \\
\text { (square } \\
\text { meters) }\end{array}$} & \multirow{3}{*}{$\begin{array}{l}\text { Furnishing } \\
\text { sequence }^{\circ}\end{array}$} & \multirow[b]{3}{*}{$\begin{array}{l}\text { Toilet } \\
\text { height } \\
\text { cm }\end{array}$} & \multirow[b]{3}{*}{$\begin{array}{c}\text { Free } \\
\text { lateral } \\
\text { space }\end{array}$} & \multicolumn{2}{|c|}{ TOILET } & & BIDET & & & SINK & & SHO & DWER \\
\hline & & & & & \multicolumn{3}{|c|}{ Handrails } & \multirow[b]{2}{*}{$\begin{array}{c}\text { Bidet } \\
\text { height } \\
\text { cm }\end{array}$} & \multirow[b]{2}{*}{$\begin{array}{c}\text { Sink } \\
\text { height } \\
\text { cm }\end{array}$} & \multirow[b]{2}{*}{$\begin{array}{l}\text { Free } \\
\text { frontal } \\
\text { space }\end{array}$} & \multirow[b]{2}{*}{$\begin{array}{l}\text { Handrail } \\
\text { height } \mathbf{c m}\end{array}$} & \multirow[b]{2}{*}{$\begin{array}{l}\text { Mirror } \\
\text { height cm }\end{array}$} & \multirow{2}{*}{$\begin{array}{c}\text { Shower } \\
\text { seat } \\
\text { height } \\
\text { cm }\end{array}$} & \multirow{2}{*}{$\begin{array}{c}\text { Horiz. } \\
\text { handrail } \\
\text { height, } \\
\text { cm }\end{array}$} \\
\hline & & & & & $\begin{array}{c}\text { Lateral } \\
\text { wall, } \\
\text { horizontal } \\
\text { type }\end{array}$ & $\begin{array}{c}\text { Lateral } \\
\text { wall, } \\
\text { vertical } \\
\text { type }\end{array}$ & $\begin{array}{c}\text { Rear wall, } \\
\text { vertical } \\
\text { type }\end{array}$ & & & & & & & \\
\hline 1 & 5,20 & 1423 & 44 & \# & 79 & $80-130$ & $\#$ & 42 & 81 & $\sqrt{ }$ & 79 & $120-200$ & \# & 87 \\
\hline 2 & 5,85 & 1423 & 51 & \# & 107 & $21-157$ & $20-160$ & 42 & 78 & $\sqrt{ }$ & $\#$ & $118-180$ & 49 & \# \\
\hline 3 & 4,53 & 1423 & 44 & $\sqrt{ }$ & \# & \# & $\#$ & 42 & 82 & $\sqrt{ }$ & $\#$ & $127-210$ & \# & 89 \\
\hline 4 & 4,65 & 1324 & 42 & $\sqrt{ }$ & \# & \# & \# & 42 & 82 & $\sqrt{ }$ & $\#$ & $120-200$ & 59 & 90 \\
\hline 5 & 3,84 & 1432 & 42 & \# & 77 & $80-137$ & $\#$ & 42 & 82 & $\sqrt{ }$ & $\#$ & $117-197$ & 59 & 89 \\
\hline 6 & 5,04 & 2341 & 42 & \# & \# & \# & \# & 42 & 80 & $\sqrt{ }$ & $\#$ & $120-200$ & 59 & 89 \\
\hline 7 & 5,33 & 2341 & 42 & \# & \# & $\#$ & \# & 42 & 81 & $\sqrt{ }$ & $\#$ & $120-200$ & 59 & 89 \\
\hline 8 & 5,08 & 1423 & 48 & \# & 80 & $23-157$ & $20-160$ & 48 & 76 & $\sqrt{ }$ & $\#$ & $125-190$ & 49 & \# \\
\hline 9 & 3,40 & 1423 & 41 & \# & \# & \# & \# & 41 & 81 & \# & \# & $130-210$ & 59 & 89 \\
\hline 10 & 4,00 & 241 & 48 & $\sqrt{ }$ & 107 & $21-157$ & $\#$ & \# & 75 & $\sqrt{ }$ & $\#$ & $115-178$ & 49 & \# \\
\hline 11 & 3,42 & 241 & 48 & $\sqrt{ }$ & \# & \# & \# & \# & 78 & $\sqrt{ }$ & $\#$ & $123-185$ & 49 & $\#$ \\
\hline 12 & 3,23 & 241 & 44 & $\sqrt{ }$ & 79 & \# & $\#$ & $\#$ & 83 & $\sqrt{ }$ & $\#$ & $127-205$ & 59 & 89 \\
\hline 13 & 3,24 & 2341 & 44 & \# & 79 & $\#$ & \# & 43 & 82 & \# & \# & $128-200$ & 57 & 89 \\
\hline 14 & 3,99 & 3241 & 43 & \# & \# & \# & \# & 41 & 82 & \# & \# & $127-205$ & 57 & 88 \\
\hline 15 & 4,14 & 1423 & 45 & $\#$ & \# & \# & \# & 43 & 83 & \# & 84 & $126-208$ & 58 & 89 \\
\hline 16 & 6,66 & 4231 & 44 & \# & \# & \# & $\#$ & 40 & 81 & \# & 80 & $128-207$ & 57 & 89 \\
\hline 17 & 6,27 & 3214 & 44 & \# & \# & \# & $\#$ & 42 & 83 & $\#$ & $\#$ & $129-205$ & \# & 89 \\
\hline 18 & 6,38 & 3241 & 44 & \# & \# & \# & \# & 41 & 82 & $\sqrt{ }$ & 80 & 127-202 & \# & 89 \\
\hline 19 & 6,38 & 1432 & 44 & \# & 80 & \# & \# & 41 & 82 & \# & 80 & $122-205$ & 59 & 89 \\
\hline 20 & 2,72 & 241 & 44 & \# & 79 & \# & \# & $\#$ & 83 & $\sqrt{ }$ & $\#$ & $124-202$ & \# & 89 \\
\hline 21 & 3,04 & 241 & 44 & \# & 79 & \# & \# & \# & 83 & $\sqrt{ }$ & \# & $128-202$ & \# & 89 \\
\hline 22 & 5,46 & 241 & 45 & $\sqrt{ }$ & 79 & \# & $70-100$ & \# & 78 & $\sqrt{ }$ & $\#$ & $126-188$ & 49 & 79 \\
\hline 23 & 4,42 & 1423 & 44 & $\sqrt{ }$ & \# & \# & \# & 42 & 82 & $\sqrt{ }$ & $\#$ & $127-205$ & \# & 89 \\
\hline 24 & 2,56 & 241 & 44 & \# & 79 & \# & \# & \# & 82 & \# & \# & $120-197$ & \# & 89 \\
\hline 25 & 2,56 & 241 & 44 & \# & 79 & \# & $\#$ & \# & 82 & $\#$ & \# & $125-203$ & \# & 89 \\
\hline 26 & 2,72 & 241 & 44 & \# & 79 & \# & \# & \# & 81 & \# & \# & $120-197$ & \# & 89 \\
\hline 27 & 2,72 & 241 & 44 & \# & 79 & \# & $\#$ & \# & 82 & $\#$ & $\#$ & $122-197$ & \# & 90 \\
\hline 28 & 4,14 & 124 & 44 & \# & 79 & \# & $70-100$ & \# & 79 & $\sqrt{ }$ & \# & $120-197$ & \# & 89 \\
\hline 29 & 3,60 & 421 & 44 & \# & 80 & \# & \# & \# & 81 & \# & \# & $120-198$ & \# & 89 \\
\hline 30 & 3,40 & 142 & 44 & $\sqrt{ }$ & \# & \# & \# & \# & 81 & $\sqrt{ }$ & \# & $120-298$ & \# & 89 \\
\hline 31 & 7,75 & 214 & 44 & $\sqrt{ }$ & $\sqrt{ }$ & $\sqrt{ }$ & $\sqrt{ }$ & \# & 82 & $\sqrt{ }$ & 80 & $120-180$ & 55 & 89 \\
\hline 32 & 7,80 & 1234 & 45 & $\sqrt{ }$ & $\sqrt{ }$ & $\sqrt{ }$ & $\sqrt{ }$ & \# & 82 & $\sqrt{ }$ & 80 & $120-180$ & 55 & 89 \\
\hline
\end{tabular}

${ }^{\circ}$ furnishing sequence: $1=$ Sink; $2=$ Toilet; $3=$ Bidet; $4=$ Shower

The symbol \# in the cell means lack of the element; the symbol $\sqrt{ }$ means its presence. 
Transfer of a dependent patient from bedroom to the en-suite bathroom with the wheelchair was possible in 10 cases up to the toilet, and in 18 cases up to the sink. Transfer of a dependent patient from bedroom to the en-suite bathroom with the mobile hoist was possible in only 3 bathrooms due to space inadequacy of the remaining bathrooms; it was possible with the shower chair and with the hygienic seat in 25 and 29 cases respectively, thanks to the maneuverability and the minimal encumbrance of these devices.

Table 5. Test of accessibility of the bed-to-bathroom path by using different devices

\begin{tabular}{llll}
\hline Device used & Dimension of device $\mathbf{( c m )}$ & Destination & Accessibility cases \\
\hline Shower stretcher & $810 \times 1989$ & Corridor bathroom & $17(53 \%)$ \\
Wheelchair & $70 \times 122$ & Sink & $18(60 \%)$ \\
Wheelchair & $70 \times 122$ & Toilet & $10(33 \%)$ \\
Mobile hoist & $112 \times 124$ & Toilet & $3(10 \%)$ \\
Shower chair & $76 \times 53$ & Shower & $25(83 \%)$ \\
Hygienic seat & $45 \times 40$ & Shower & $29(96 \%)$ \\
\hline
\end{tabular}

\subsection{Critical aspects identified by reports}

Some factors inherent the physical layout were identified as critical from the nurses and patients' reports for safety, usability and accessibility.

\subsubsection{Space}

Storage space is always critical in the ward and the two corridor bathrooms were dedicated to this function; it seems that nurses in this rehabilitation ward are dissuaded from properly using these two bathrooms for collaborative or partially dependent patients because of the non-en suite features and the excessively specialized equipment specifically furnished for highly dependent patients;

Transferring and assisting the patients was sometimes laborious even in large bathrooms, due to obstructed path from bed and large distances between hygienic elements; without adequate supports, nurse had to assist the patient with greater effort and with increased biomechanical risk;

In some bathrooms the restricted spaces didn't allow the collaborative and partially dependent patient and the assistant nurse to move without tripping or to use the appropriate devices in an adequate way; trip and falls, overload, and time dispersion were the major risks emerging from this scenario. Excessively narrow transit and standing zones prevented the nurses from adequately assisting the patients or forced the nurses into extreme and fatiguing postures.

\subsubsection{Location of elements}

Inconsistencies and discrepancies in the elements' location in bathrooms affected safety and usability during toileting related tasks. For example, shower seats fixed at an excessive height in respect to the standard wheelchair seat could require awkward movements and excessive effort to the patient and the nurse; differences in the location sequence of the hygienic elements in every bathrooms could disconcert the assisting nurse and cause uncertainty in the equipment choice. A large distance between elements or the lack of proper located handrails decrease safety and usability during postural transfers and could lead to awkward motions, loss of balance or compensatory behaviors possibly causing injury.

The toiletries location was sometimes outside the limit of accessibility for the wheel-chaired patient; shelf and mirrors, shower taps and coat hooks located at an excessive height were inaccessible for most seated patients; reduced or missed usability and satisfaction resulted, possibly decreasing patient's participation. 
The movements required for the toileting-related tasks should be within the patient's comfortable and physiological limits; toilet flushing and toilet paper holder positioned on the rear wall required trunk rotation and changes in body posture which are difficult or harmful for most patients.

\subsubsection{Equipment}

The provision of handrails was incomplete and their location was inconsistent. Moreover, the similarity in size and form, combined with important differences in sturdiness, between handrails and towel holders made the latter a potential risk for patients who mistakenly tried to use the towel holders as supportive handrails. The discontinuity of handrails along the bedroom-to-bathroom path increased the danger of falls.

The shower seats were only partially provided and some of them were not firmly fixed to the wall, thereby increasing the risk of fall in case of overweight patients; in some cases they were fixed at an excessive height if compared to the standard wheelchair seat, requiring additional effort by the assisting nurse.

A level shower flooring was judged very good for accessibility but it often had the negative effect of become slippery if wet; optimal drainage and maintenance of the shower area should be regularly checked and maintained by the technical personnel.

\subsubsection{Critical aspects identified by observations}

Some inappropriate behaviors possibly undermining safety and induced by lack or deficiencies in the design, were noted; for example the patient/assistant could be induced to place a plastic, unstable chair in the shower area to replace the missing shower seat (see the figure). Compensatory behaviors are often adopted by patients or nurses where functions are lacking or inappropriate.

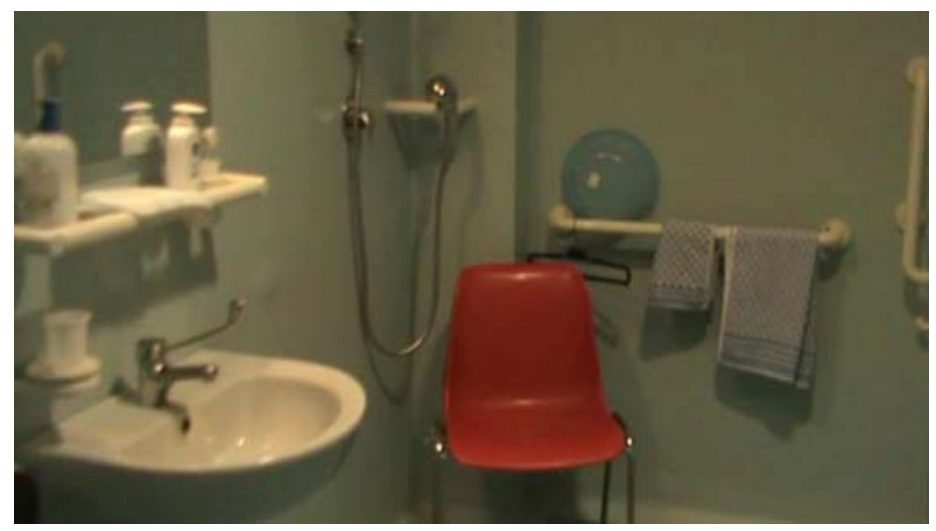

Figure. Inadequate adaptation of a shower seat

Additional concerns were raised, comparing the observed bathrooms and their use:

Obese patients require enlarged rooms and specific equipment with special dimension, weight capacity and sturdiness; for example the bariatric toilet should be steel-made with enlarged free access room at sides. Traction handrails should be floor (and not wall) mounted, to prevent accidental rupture. Most of the bathrooms studied, were unsuitable for obese patients, in terms of both space and equipment;

Frail, elderly or sensorily- impaired patients necessitate a clear path and continuous support en route from bedroom to and inside bathroom, and extra color contrast between hygienic elements and their surroundings. Handrail height at $80 \mathrm{~cm}$ was deemed inadequate for frail patients, suggesting instead two different levels $(66 \mathrm{~cm}$ and $91 \mathrm{~cm}$ ) in order to adapt to various anthropometric sizes and motor capabilities ${ }^{[17]}$. Similarly, door handles and light switches should be lowered at $70 \mathrm{~cm}$ in order to be accessible for most patients; 
In emergency situations, when several staff members must enter the bathroom to rescue a patient, restricted space could severely hamper the technical tasks; the bathroom's area should comfortably allocate at least two assistants and the equipment.

Organizational and educative staffing aspects determine how structural factors impact on safety. Nurses should assess the hygienic needs of each patients and provide the necessary equipment, in order to perform safe transfers and adopt adequate devices. Availability of the correct equipment should be assured in any ward, according to the patients' characteristics and considering that stable, secure, compact, light in weight, easy to carry and clean devices are best suited to assist partially dependent patients ${ }^{[28]}$. Usability and accessibility of devices should be checked in each room, also assuming the occurrence of an emergency, possibly providing for technological innovation or space renovation.

Independent patients should be encouraged to actively use the bathroom when a proper physical layout is provided in the bedroom and bathroom.

\section{Discussion}

As for the universal type hospital room area ${ }^{[7,23,29]}$, wider spaces in bathrooms should be rated by a flexible design in order to accomplish different needs and to reduce the assistants' effort during toileting tasks. Adequate spaces should be ideally posted in the planning phase as the basic assumption of functional buildings' design, providing for extra large rooms which account for bulky equipment, nursing assistance and obese accommodation ${ }^{[23,30]}$.

The design regulation relative to space and equipment has to be integrated by ergonomic considerations, as provided from the participatory approach and the universal design principles, helping to achieve better results in safety, accessibility and usability during the assistance hygienic tasks. Adaptation of bathrooms in the still existing buildings should be based on the ergonomic criteria and the patient-centered vision, for example providing for proper location of elements and handrails which enable the patient and the nurse to safely manage the transfers.

Space and design of bathrooms in a rehabilitation ward should fulfill safety requirements allowing the independent patient to actively participate in hygiene tasks, and the dependent patient to be assisted with appropriate equipment avoiding overload of the personnel. Assistance equipment should be matched with the patient's needs and condition, and their usability should be checked in every space.

Ideally a more flexible design and larger rooms could face the care needs of a population becoming increasingly older and more frail, permitting further and continuous adjustments in the organizational work setting so to respond to the needs of most users ${ }^{[7]}$ and be decisive in creating safe workplaces to drastically reduce the incidence of musculoskeletal disorders in nurses ${ }^{[20]}$.

This observational study, within the limits of a very basic design, contributes to the understanding of fundamental ergonomic aspects relative to bathroom and hygiene use from the perspective of both the patient and the assisting nurse.

Hitherto, within the ergonomic literature, little emphasis has been placed on the relevance of environment design and bathroom-related activities, in that ergonomic research has failed to create a homogenous corpus of literature dealing with the potential risk affecting the patient and nurse population in this specific context. Nevertheless, hygiene and care related activities have a relevant intrinsic rehabilitative value for the patient, and are of primary importance for safety and security of the nurse. Further studies should be focused on safety, accessibility and usability of the hospital environment from a user perspective in order to gain evidence-based healthcare facility design and provide stimulus for technological innovation of devices. 


\section{Conclusions}

Inadequacies revealed by our participative survey mainly concerned restricted or poorly fitted spaces, scant or missed supporting elements (handrails, shower seats) and inconsistencies in their location. Apart from renovation, which requires extensive finance and time allocation, some easy to apply solutions were identified in collaboration with the ward nurses, about the provision of hygienic seats and proper located handrails, in order to expand accessibility to the bathrooms and ensure safe transfers. Adherence to regulations is not enough to achieve accessibility and usability for any user; indeed, it should be integrated by the ergonomic approach, which is exhaustive in considering the relation between the acting individual and the environment.

\section{References}

[1] Carayon P, et al. Macroergonomics in Healthcare Quality and Patient Safety. Rev Hum Factors Ergon. 2013; 8(1): 4-54. PMid:24729777 http://dx.doi.org/10.1177/1557234X13492976

[2] Nelson A, Baptiste AS. Evidence-based practices for safe patient handling and movement. Orthopaedic Nursing. 2006; 2(6): 366-379.

[3] Nelson A, Lloyd J, Menzel N, Gross C. Preventing nursing back injuries: redesigning patient handling tasks. AAOHN Journal. 2003; 51: 126-134. PMid:12670100

[4] Osha. Guidelines for nursing homes. US Department of Labour. 2005.

[5] ISO TR 12296; 2012. Ergonomics. Manual handling of people in the healthcare sector.

[6] CABE. The Role of Hospital Design in the Recruitment, Retention and Performance of Nurses in England. The Commission of Architecture and the Built Environment, London. 2004. Available from: http://www.healthyhospitals.org.uk/index.html.

[7] Hignett S, Lu J. Space to care and treat safely in acute hospitals: Recommendations from 1866 to 2008. Applied Ergonomics 2010; 41: 666-673. PMid:20106467 http://dx.doi.org/10.1016/j.apergo.2009.12.010

[8] Hignett S, Masud T. A review of environmental hazards associated with in-patient falls. Ergonomics. 2006; 49(5): 605-616. PMid:16717012 http://dx.doi.org/10.1080/00140130600568949

[9] Stichler JF. Is Your Hospital Hospitable? How Physical Environment Influences Patient Safety. AWHONN. 2007 ; 506-511. PMid:17897432

[10] Reiling JG, Knutzen BL, Wallen TK, McCullough S, Miller R, Chernos S. Enhancing the traditional hospital design process: a focus on patient safety. Joint Commission Journal on Quality and Safety. 2004; 30(3):115-124. PMid:15032068

[11] Department of Health/Design Council. Design for Patient Safety. A Scoping Study to Identify How the Effective Use of Design Could Help to Reduce Medical Accidents. London: Department of Health. 2003.

[12] Joint Commission on Accreditation of Healthcare Organizations, JCAHO. National Patient Safety Goals. 2004.

[13] Grout J. Mistake-proofing the design of health care process. Rockville, MD: Agency for Healthcare Research and Quality and U.S. Department of Health and Human Services. 2007.

[14] Nelson A. Safe patient handling and movement. A practical guide for health care professionals. Springer Publishing Company, New York; 2006.

[15] Chamberlain MA, Stowe J. Bathing in hospital. British medical journal. 1982; 284:1693-1694. http://dx.doi.org/10.1136/bmj.284.6330.1693

[16] Monro A, Mulley GP. Hospital bathrooms and showers: a continuing saga of inadequacy. J R Soc Med. 2004; 97(5): 235-7. http://dx.doi.org/10.1258/jrsm.97.5.235

[17] Tzeng HM, Yin CY. Adding additional grab bars as a possible strategy for safer hospital stays. Applied Nursing Research. 2010; 23: 45-51. PMid:20122510 http://dx.doi.org/10.1016/j.apnr.2008.05.003

[18] Tzeng HM. Understanding the Prevalence of Inpatient Falls Associated With Toileting in Adult Acute Care Settings. Nurs Care Qual. 2010; 25 (1): 22-30. PMid:19553863 http://dx.doi.org/10.1097/NCQ.0b013e3181afa321

[19] Fink N, Pak R, Battisto D. Developing a usability evaluation tool to assess the patient room bathroom. Herd. 2010; 3(3): 22-41. PMid:21165859

[20] Stichler JF, Feiler, J.L. Ergonomics in Healthcare Facility Design, Part 1. Patient Care Areas. JONA. 2011; 41(2): $49-51$. PMid:21266880 http://dx.doi.org/10.1097/NNA.0b013e31820592e6

[21] Tzeng HM, Yin CY. The extrinsic risk factors for inpatient falls in hospital patient rooms. J Nurs Care Qual. 2008; $23(3): 233-41$. PMid:18562866 http://dx.doi.org/10.1097/01.NCQ.0000324588.91837.84 
[22] Tzeng HM, Yin CY. Toileting-related inpatient falls in adult acute care settings. Medsurg Nurs. 2012; 21(6): 372-7. PMid:23477031

[23] Hamilton DK. Design for Patient Units, 2003. Available from: http://www.muhc-healing.mcgill.ca/english/Speakers/hamilton_p2.html

[24] Nielsen J. Usability Engineering. AP Professional. Cambridge, MA, 1993.

[25] Guay M, Desrosiers J, Dubois MF. Criterion validity of a home health aide' s algorithm for recommending bathroom equipment. Canadian Journal of occupational therapy. 2009; 76: 246-256. PMid:19757730

[26] Boston-Fleischhauer C. Enhancing Healthcare Process Design with Human Factors Engineering and Reliability Science, Part 1. JONA. 2008; 38(1): 27-32.

[27] Health Department. RAI, Resident Assessment Instrument. USA. 1991. PMid:18157002 http://dx.doi.org/10.1097/01.NNA.0000295632.80345.3d

[28] Tzeng HM. A feasibility study of providing folding commode chairs in patient bathrooms to reduce toileting-related falls in an adult acute medical-surgical unit. J Nurs Care Qua. 2011; 26(1): 61-68. PMid:22914667 http://dx.doi.org/10.1097/NCQ.0b013e3181d94f4d

[29] Hendrick AL, Fay J, Sorrells A. Effects of acuity-adaptable rooms on flow of patients and delivery of care. American Journal of Critical Care. 2004; 13: 35-45.

[30] Chaudhury H, Mahmood A, Valente M. Advantages and disadvantages of single-versus-multiple-occupancy rooms in acute care environments. Environment and Behaviour. 2005; 37(6): 760-786. http://dx.doi.org/10.1177/0013916504272658 